\title{
ALTERNATIF PEMECAHAN MASALAH KETERLAMBATANPENYELESAIAN PROYEK (STUDI KASUS PEMBANGUNAN GEDUNG PUSKESMAS LAREN KABUPATEN LAMONGAN)
}

\author{
Fridha Guivanny Putri ${ }^{1}$, Rio Rahma Dana ${ }^{2}$ \\ ${ }^{1}$ Program Studi Teknik Sipil Fakultas Teknik Sipil Universitas Islam Lamongan, \\ ${ }^{2}$ Dosen Program Studi Teknik Sipil Fakultas Teknik Universitas Islam Lamongan, \\ Email :gfridha@gmail.com; riorahma@yahoo.com.id
}

\begin{abstract}
Abstrack
The successfulness of executing the construction projects right on time is one of the most important goals both for the owners and contractors. In general, each construction project has a specific implementation plan and schedule of implementation. It contains some important things, for example when the project should begin, when it should be completed, and how to provide the resources. As in the development project of Public Health Center building in LarenDistrict, Lamongan Regency in 2016 which has been delayed up to six weeks, causing inaccuracy between the planningschedule anddevelopment implementation. This research aims to be used as an evaluation to get the fastest acceleration time by using cut and crashing method. From the data obtained fromthe time schedule, cost estimate plan (RAB), wage price analysis, and project materials, the next step is making the job network and determining the critical pathfor cut and crash method. The results of the study show that the project acceleration can be done up to 82 days or 7 days faster than the normal day, that is 89 days with acceleration cost of Rp. 347.935.000,00 or increased from the normal cost of Rp. $345.390 .000,00$. The percentage of the selected acceleration time ratio is approximately $6.02 \%$ faster than the normal time, while for the acceleration cost is approximately $0.68 \%$ greater than the normal cost. Therefore, with this research, the work actually can be completed on December 13, 2016.
\end{abstract}

Keywords: Public Health Center of Laren District, cut and crash, network, critical path

\section{PENDAHULUAN}

Keberhasilan melaksanakan proyek konstruksi tepat waktunya adalah salah satu tujuan terpenting, baik bagi pemilik maupun kontraktor. Pada umumnya setiap proyek konstruksi mempunyai rencana pelaksanaan dan jadwal pelaksanaan yang tertentu, kapan pelaksanaan proyek tersebut harus dimulai, kapan harus diselesaikan dan bagaimana penyediaan sumber dayanya.Pembuatan jadwal pelaksanaan proyek selalu mengacu pada kondisi prakiraan yang ada pada saat rencana dan jadwal tersebut dibuat, karena itu masalah akan timbul apabila terjadi ketidaksesuaian antara prakiraan dengan pelaksanaan di lapangan, dampak umum yang terjadi adalah keterlambatan waktu pelaksanaan proyek, disamping meningkatnya biaya pelaksanaan proyek.

Seperti pada proyek pembangunan gedung Puskesmas di Kecamatan Laren Kabupaten Lamongan tahun 2016 lalu yang mengalami keterlambatan pada mingu ke 6 , sehingga menimbulkan ketidak-tepatan antara jadwal perencanaan dan jadwal pelaksanaan pembangunan. Adapun gedung ini akan difungsikan sebagai fasilitas penunjang. Dalam pelaksanaannya terdapat banyak kendala yang dihadapi terutama pada pelaksanaan struktur, seperti kurang efektifnya tenaga kerja atau sehingga hal ini menyebabkan pekerjaan terselesaikan dengan waktu yang cukup lama. Dari data yang diperoleh dari pihak pelaksana proyek 
terselesaikan selama 89 hari kerja atau terselesaikan pada tanggal 19 Desember 2016, dengan perbandingan progress pelaksanaan pada kurva $\mathrm{S}$ yang berbeda dengan perencanaan.

Berdasarkan latar belakang di atas maka dilakukan percepatan waktu menggunakan jalur kritis dengan cut and crash.

Adapun maksud dan tujuan dari penelitian iniantara lain sebagai evaluasi untuk mengetahui berapa lama waktu paling cepat akibat percepatan proyek menggunakan metode jalur kritis cut and crash dan untuk mengetahui berapa besar biaya akibat percepatan proyek menggunakan metode jalur kritis cut and crash serta untuk mengetahui berapa presentase perbandingan waktu dan biaya proyek sebelum dan sesudah adanya percepatan menggunakan metode jalur kritis Cut and Crash.

\section{METODE PENELITIAN}

Metode penelitian yang digunakan adalah dengan menganalisa data - data yang didapatkan dari proyek pelaksanaan pembangunan gedung Puskesmas Laren.

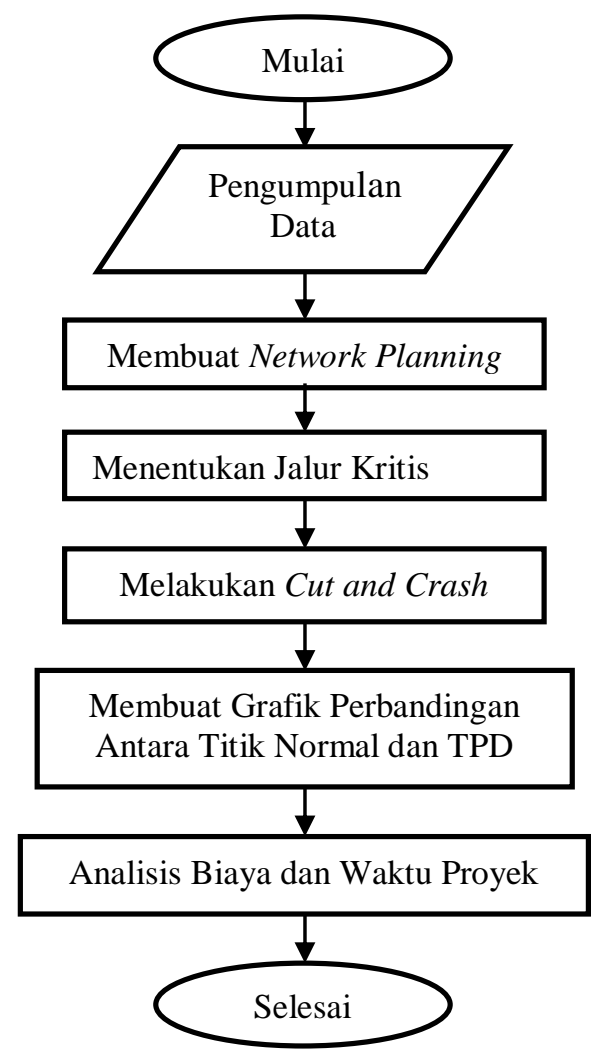

Gambar. 1

Diagram Alur Penelitian
3. HASIL DAN PEMBAHASAN

Menyusun Jaringan Kerja (Network Planning)

Penyusunan network planning dimulai dengan menginput 83 uraian kegiatan pada Microsoft Project 2007 (software yang digunakan untuk mengelola proyek), kemudian mengisi predecessor setiap kegiatan proyek dengan acuan time schedule di lapangan.Setelah menginputkan data durasi di Microsoft Project 2007, dilakukan perhitungan jumlah tenaga kerja berdasarkan koefisien pada Analisa Harga Satuan Pekerjaan.

\section{Menentukan Kegiatan Kritis}

Berdasarkan jaringan kerja yang telah dibuat dengan menggunakan Microsoft Project 2007 tadi, maka secara otomatis dari 83 uraian kegiatan dapat diketahui pekerjaan apa saja yang ada pada jalur kritis.

Tabel. 1

\section{Daftar Kegiatan Kritis dan Durasi serta Biaya Tenaga Kerja Kegiatan Kritis}

\begin{tabular}{|c|c|c|c|c|c|c|}
\hline $\begin{array}{c}\text { URAIAN } \\
\text { KEGIATAN }\end{array}$ & $\begin{array}{l}\text { WAKTU } \\
\text { (Hari) }\end{array}$ & $\mathbf{P}$ & $\mathbf{T}$ & KT & $\mathbf{M}$ & $\begin{array}{c}\text { BIAYA } \\
\text { TENAGA } \\
\text { KERJA (Rp) }\end{array}$ \\
\hline $\begin{array}{l}\text { Pek. Ring } \\
\text { Balok (B5) } \\
15 \times 15 \mathrm{~cm}\end{array}$ & 8 & 3 & 2 & 1 & 1 & $3,680,000$ \\
\hline $\begin{array}{l}\text { Pek. Plat } \\
\text { Teras \& } \\
\text { Kanopi t.10 } \\
\text { cm }\end{array}$ & 8 & 5 & 2 & 1 & 2 & $5,200,000$ \\
\hline $\begin{array}{l}\text { Balok Pintu } \\
\text { Geser } 15 \times 25\end{array}$ & 8 & 9 & 4 & 1 & 1 & $7,440,000$ \\
\hline $\begin{array}{l}\text { Pas. Bata } \\
\text { merah } 1: 6\end{array}$ & 24 & 8 & 3 & 1 & 1 & $20,640,000$ \\
\hline $\begin{array}{l}\text { Pek. Kap } \\
\text { Atap } \\
\text { Galvalum } \\
\text { Fabrikasi }\end{array}$ & 10 & 6 & 3 & 1 & 1 & $6,950,000$ \\
\hline $\begin{array}{l}\text { Pas. Genteng } \\
\text { Fabrikasi }\end{array}$ & 6 & 9 & 5 & 1 & 1 & $6,000,000$ \\
\hline $\begin{array}{l}\text { Pas. Genteng } \\
\text { Bubungan } \\
\text { Fabrikasi }\end{array}$ & 4 & $\begin{array}{l}1 \\
0\end{array}$ & 5 & 1 & 1 & $4,220,000$ \\
\hline \multicolumn{5}{|c|}{$\begin{array}{c}\text { JUMLAH BIAYA TENAGA } \\
\text { KERJA KEGIATAN KRITIS }\end{array}$} & & $54,130,000$ \\
\hline \multicolumn{7}{|c|}{ Sumber : Hasil Perhitungan } \\
\hline $\begin{array}{c}\text { Melakuka } \\
\text { Meliha } \\
\text { dilakukan }\end{array}$ & $\begin{array}{l}\text { Crash } \\
\text { kond } \\
\text { crashp }\end{array}$ & & & $\begin{array}{l}\text { lur } \\
\text { semu }\end{array}$ & $\begin{array}{l}\text { kriti } \\
\text { da }\end{array}$ & $\begin{array}{l}\text { is maka } \\
\text { kegiatan }\end{array}$ \\
\hline
\end{tabular}


berdasarkan penambahan tenaga kerja. Setelah dilakukan crash, nilai slope tiap pekerjaan pun dapat dihitung untuk mempermudah melakukan proses cut pada kegiatan yang diinginkan.

Rumus yang digunakan :

Kap.Prod Tenaga Kerja :

K.P Tenaga Kerja $=\frac{\text { Satuan Pekerjaan }}{\text { Koefisien Tenaga Kerja }} \ldots . . . . .($ 1)

Jumlah Tenaga Kerja :

Jumlah T.K $=\frac{\text { Volume Pekerjaan }}{\text { K.P Tenaga Kerja x Durasi }} \ldots$

Durasi :

Durasi $=\frac{\text { Volume Pekerjaan }}{\text { K.P Tenaga Kerja x Jumlah T.K }}$

Contoh Perhitungan :

- Pekerjaan Pasangan Bata Merah 1: 6

Diketahui :

Durasi $=26$ hari

Koefisien Upah Pekerja $=0,3000$ oh

Koefisien Upah Tukang $=0,1000$ oh

Koefisien Upah Kepala Tukang $=0,010 \mathrm{oh}$

Koefisien Upah Mandor $=0,0150$ oh

(Koefisien didapat dari analisa upah dan bahan)

Volume Pekerjaan $=649,720 \mathrm{~m}^{2}$

Satuan Pekerjaan $=1 \mathrm{~m}^{2}$

Jumlah Pekerja $=8$ org $/ \mathrm{hr}$

Jumlah Tukang $=3 \mathrm{org} / \mathrm{hr}$

Jumlah K. Tukang $=1 \mathrm{org} / \mathrm{hr}$

Jumlah Mandor $=1 \mathrm{org} / \mathrm{hr}$

Biaya Tenaga Kerja $=20.930 .000,00$

Tenaga Kerja Pekerja di crash $50 \%$

Jumlah Pekerja Crash $=8+(50 \%$ x 8$)$

$$
=12 \text { org }
$$

Durasi Crash $=649.720 /(1 / 0,3000 \times 12$

\section{Cut and Crash :}

$$
\text { org) }=17 \text { hari }
$$

Jumlah Tukang Crash $=5$ org

Jumlah K.Tukang Crash $=2$ org

Jumlah Mandor Crash $=2$ org

Biaya Tenaga Kerja Crash

$$
\begin{aligned}
= & (12 \times 17 \times 55.000)+(5 \times 17 \times 70.000)+ \\
& (2 \times 17 \times 75.000)+(2 \times 17 \times 80.000) \\
= & 22.440 .000
\end{aligned}
$$

Tabel. 2

Hasil Perhitungan Durasi dan Biaya Sesudah dilakukan Percepatan

\begin{tabular}{ccccccc}
\hline URAIAN & WAKTU & P & T & KT & M & $\begin{array}{c}\text { BIAYA } \\
\text { TENAGA } \\
\text { KERJA } \\
\text { KEASANAN }\end{array}$ \\
\hline
\end{tabular}

Pek. Ring

$\begin{array}{lllllll}\text { Balok } & 5 & 5 & 3 & 2 & 2 & 3,975,000\end{array}$

\begin{tabular}{|c|c|c|c|c|c|c|}
\hline $\begin{array}{l}\text { Balok Pintu } \\
\text { Geser } 15 \times 25\end{array}$ & 6 & 14 & 6 & 2 & 2 & $9,000,000$ \\
\hline $\begin{array}{l}\text { Pas. Bata } \\
\text { merah } 1: 6\end{array}$ & 15 & 12 & 5 & 2 & 2 & $22,440,000$ \\
\hline $\begin{array}{l}\text { Pek. Kap Atap } \\
\text { Galvalum } \\
\text { Fabrikasi }\end{array}$ & 6 & 9 & 5 & 2 & 2 & $6,930,000$ \\
\hline $\begin{array}{l}\text { Pas. Genteng } \\
\text { Fabrikasi }\end{array}$ & 4 & 14 & 8 & 2 & 2 & $6,560,000$ \\
\hline $\begin{array}{l}\text { Pas. Genteng } \\
\text { Bubungan } \\
\text { Fabrikasi } \\
\end{array}$ & 3 & 15 & 8 & 2 & 2 & $5,085,000$ \\
\hline
\end{tabular}

(B5) $15 \times 15 \mathrm{~cm}$

Pek. Plat Teras

$\begin{array}{lllllll}\& \text { Kanopi t.10 } & 5 & 8 & 3 & 2 & 3 & 5,200,000\end{array}$

$\mathrm{cm}$

\section{Menentukan Nilai Slope}

Setelah dilakukan Crash pada pekerjaan kritis, nilai slope dapat ditentukan dengan Rumus:

Slope $=\frac{\text { Biaya Crash } \text {-Biaya Normal }}{\text { Waktu Normal-Waktu Crash }}$

Contoh Perhitungan :

- Pekerjaan Ring Balok (B5) 15 x15 cm

Diketahui :

Durasi Normal $=8$ hari

Durasi Crash $=5$ hari

Biaya Normal $=$ Rp. $3.680 .000,00$

Biaya Crash $=$ Rp. 3.975.000,000

Biaya Slope $=(3.975 .000-3.680 .000):$

$(8-5)$

$=98.333$

Tabel. 3

Nilai Slope Kegiatan Kritis

\begin{tabular}{lc}
\hline \multicolumn{1}{c}{ URAIAN KEGIATAN } & SLOPE (Rp) \\
\hline Pek. Ring Balok (B5) $15 \times 15 \mathrm{~cm}$ & 98,333 \\
\hline Pek. Plat Teras \& Kanopi t.10 cm & - \\
\hline
\end{tabular}




\begin{tabular}{lc}
\hline \multicolumn{1}{c}{ URAIAN KEGIATAN } & SLOPE $($ Rp) \\
\hline Balok Pintu Geser $15 \times 25$ & 780,000 \\
\hline Pas. Bata merah $1: 6$ & 200,000 \\
\hline Pek. Kap Atap Galvalum Fabrikasi & 5,000 \\
\hline Pas. Genteng Fabrikasi & 280,000 \\
\hline Pas. Genteng Bubungan Fabrikasi & 865,000 \\
\hline \multicolumn{2}{c}{ Sumber : Hasil Perhitungan }
\end{tabular}

Setelah perhitungan slope pada tiap pekerja kritis dilakukan pemotongan durasi.

Proses cutting pada penelitian ini mencoba mereduksi durasi pekerjaan dengan penambahan jumlah pekerja dari tenaga kerja sebanyak $50 \%$.

Pada penelitian ini pengelompokkan cutting dibagi menjadi 5 kelompok berdasarkan besarnya biaya slope.

Kelompok 1 : slope Rp. 0.000,00 s/d Rp. $500.000,00$

Kelompok 2 : slope Rp. 500.000,00 s/d Rp. $1.000 .000,00$

Tabel. 4

Kelompok Pekerjaan Kritis dalam $\mathrm{Cut}$

\begin{tabular}{clc}
\hline $\begin{array}{c}\text { KELOMPOK } \\
\text { CUTTING }\end{array}$ & \multicolumn{1}{c}{$\begin{array}{c}\text { URAIAN } \\
\text { KEGIATAN }\end{array}$} & $\begin{array}{c}\text { SLOPE } \\
\text { (Rp) }\end{array}$ \\
\hline & $\begin{array}{l}\text { Pek. Plat Teras \& } \\
\text { Kanopi t.10 cm }\end{array}$ & - \\
\cline { 2 - 3 } & $\begin{array}{l}\text { Pek. Kap Atap } \\
\text { Galvalum Fabrikasi }\end{array}$ & 5,000 \\
\cline { 2 - 3 } Kelompok 1 & $\begin{array}{l}\text { Pek. Ring Balok } \\
\text { (B5)15x15 cm }\end{array}$ & 98,333 \\
\cline { 2 - 3 } & $\begin{array}{l}\text { Pas. Bata merah 1 : } \\
6\end{array}$ & 200,000 \\
\cline { 2 - 3 } & $\begin{array}{l}\text { Pas. Genteng } \\
\text { Fabrikasi }\end{array}$ & 280,000 \\
\hline & $\begin{array}{l}\text { Balok Pintu Geser } \\
\text { 15x25 }\end{array}$ & 780,000 \\
\cline { 2 - 3 } & $\begin{array}{l}\text { Pas. Genteng } \\
\text { Bubungan Fabrikasi }\end{array}$ & 865,000 \\
\hline
\end{tabular}

Sumber : Hasil Pengamatan

\section{Pemotongan Pekerjaan Kritis (Cut)}

Proses cutting dilakukan mulai dari pekerjaan kritis yang memiliki nilai slope terkecil dengan kombinasi yang berbeda hingga tidak ditemukan lagi kegiatan kritis setelah dilakukan cutting. Jika setelah dilakukan cutting masih ditemukan kegiatan kritis, maka dilakukan cutting lagi pada pekerjaan kritis lain.

Untuk cut and crash 1 merupakan pemotongan durasi dari kelompok slope 1, untuk cut and crash 2 merupakan pemotongan durasi dari kelompok slope 2, dan sedangkan untuk cut and crash 3 merupakan pemotongan durasi dari kombinasi kedua kelmpok durasi. Berikut merupakan tabel perubahan kegiatan kritis (K) serta non-kritis (NK) dan durasi total proyek setelah dilakukan metode cut and crash.

Tabel. 5

Perubahan Pekerjaan Kritis dalam Proses Cut and Crash

\begin{tabular}{|c|c|c|c|c|}
\hline \multirow{2}{*}{$\begin{array}{l}\text { URAIAN } \\
\text { KEGIATAN }\end{array}$} & \multirow{2}{*}{ NORMAL } & \multicolumn{3}{|c|}{$\begin{array}{c}\text { CUTAND } \\
\text { CRASHING }\end{array}$} \\
\hline & & 1 & 2 & 3 \\
\hline $\begin{array}{l}\text { Pek. Ring } \\
\text { Balok } \\
\text { (B5) } 15 \times 15 \\
\text { cm }\end{array}$ & $\mathrm{K}$ & NK & $\mathrm{K}$ & NK \\
\hline $\begin{array}{l}\text { Pek. Plat } \\
\text { Teras \& } \\
\text { Kanopi t.10 } \\
\text { cm }\end{array}$ & $\mathrm{K}$ & NK & $\mathrm{K}$ & NK \\
\hline $\begin{array}{l}\text { Balok Pintu } \\
\text { Geser } 15 \times 25\end{array}$ & $\mathrm{~K}$ & NK & NK & NK \\
\hline $\begin{array}{l}\text { Pas. Bata } \\
\text { merah } 1: 6\end{array}$ & $\mathrm{~K}$ & NK & $\mathrm{K}$ & NK \\
\hline $\begin{array}{l}\text { Pek. Kap } \\
\text { Atap } \\
\text { Galvalum } \\
\text { Fabrikasi }\end{array}$ & $\mathrm{K}$ & NK & $\mathrm{K}$ & NK \\
\hline $\begin{array}{l}\text { Pas. Genteng } \\
\text { Fabrikasi }\end{array}$ & $\mathrm{K}$ & NK & $\mathrm{K}$ & NK \\
\hline $\begin{array}{l}\text { Pas. Genteng } \\
\text { Bubungan } \\
\text { Fabrikasi }\end{array}$ & $\mathrm{K}$ & NK & $\mathrm{K}$ & NK \\
\hline $\begin{array}{c}\text { DURASI } \\
\text { (Hari) }\end{array}$ & 84 & 71 & 80 & 71 \\
\hline
\end{tabular}

\section{Analisis Biaya dan WaktuPercepatan}

Tabel. 6

Biaya dan Waktu Proyek Cut and Crash 1

\begin{tabular}{|c|c|c|c|c|c|c|}
\hline $\begin{array}{l}\text { URAIAN } \\
\text { KEGIATAN }\end{array}$ & WAKTU & $\mathbf{P}$ & $\mathbf{T}$ & KT & M & $\begin{array}{c}\text { BIAYA } \\
\text { TENAGA } \\
\text { KERJA (Rp) }\end{array}$ \\
\hline $\begin{array}{l}\text { Pek. Ring } \\
\text { Balok } \\
\text { (B5) } 15 \times 15 \mathrm{~cm}\end{array}$ & 5 & 5 & 3 & 2 & 2 & $3,975,000$ \\
\hline
\end{tabular}




\begin{tabular}{|c|c|c|c|c|c|c|}
\hline $\begin{array}{l}\text { URAIAN } \\
\text { KEGIATAN }\end{array}$ & WAKTU & $\mathbf{P}$ & $\mathbf{T}$ & KT & $\mathbf{M}$ & $\begin{array}{c}\text { BIAYA } \\
\text { TENAGA } \\
\text { KERJA (Rp) }\end{array}$ \\
\hline $\begin{array}{l}\text { Pek. Plat } \\
\text { Teras \& } \\
\text { Kanopi t.10 } \\
\text { cm }\end{array}$ & 5 & 8 & 3 & 2 & 3 & $5,200,000$ \\
\hline $\begin{array}{l}\text { Pek. Kap Atap } \\
\text { Galvalum } \\
\text { Fabrikasi }\end{array}$ & 6 & 9 & 5 & 2 & 2 & $6,930,000$ \\
\hline $\begin{array}{l}\text { Pas. Genteng } \\
\text { Fabrikasi }\end{array}$ & 4 & 14 & 8 & 2 & 2 & $6,560,000$ \\
\hline
\end{tabular}

\begin{tabular}{ll}
\hline Jumlah Biaya Tenaga Kerja & $45,105,000$ \\
\hline Sumber : Hasil Perhitungan
\end{tabular}

Tabel. 7

Biaya dan Waktu Proyek Cut and Crash 2

\begin{tabular}{lccccccc}
\hline $\begin{array}{l}\text { URAIAN } \\
\text { KEGIATAN }\end{array}$ & WAKTU & $\mathbf{P}$ & $\mathbf{T}$ & $\mathbf{K T}$ & $\mathbf{M}$ & $\begin{array}{c}\text { BIAYA } \\
\text { TENAGA } \\
\text { KERJA (Rp) }\end{array}$ \\
\hline $\begin{array}{l}\text { Balok Pintu } \\
\text { Geser 15x25 }\end{array}$ & 6 & 14 & 6 & 2 & 2 & $9,000,000$ \\
\hline $\begin{array}{l}\text { Pas. } \\
\begin{array}{l}\text { Genteng } \\
\text { Bubungan } \\
\text { Fabrikasi }\end{array}\end{array}$ & 3 & 15 & 8 & 2 & 2 & $5,085,000$ \\
\hline
\end{tabular}

Jumlah Biaya Tenaga Kerja $\quad 14,085,000$
Sumber :Hasil Perhitungan

Tabel. 8

Biaya dan Waktu Proyek Cut and Crash 3

\begin{tabular}{|c|c|c|c|c|c|c|}
\hline $\begin{array}{l}\text { URAIAN } \\
\text { KEGIATAN }\end{array}$ & WAKTU & $\mathbf{P}$ & $\mathbf{T}$ & KT & $\mathbf{M}$ & $\begin{array}{c}\text { BIAYA } \\
\text { TENAGA } \\
\text { KERJA } \\
(\text { Rp) } \\
\end{array}$ \\
\hline $\begin{array}{l}\text { Pek. Ring } \\
\text { Balok } \\
\text { (B5) } 15 \times 15 \mathrm{~cm}\end{array}$ & 5 & 5 & 3 & 2 & 2 & $3,975,000$ \\
\hline $\begin{array}{l}\text { Pek. Plat } \\
\text { Teras \& } \\
\text { Kanopi t.10 } \\
\text { cm }\end{array}$ & 5 & 8 & 3 & 2 & 3 & $5,200,000$ \\
\hline $\begin{array}{l}\text { Balok Pintu } \\
\text { Geser } 15 \times 25\end{array}$ & 6 & 14 & 6 & 2 & 2 & $9,000,000$ \\
\hline $\begin{array}{l}\text { Pas. Bata } \\
\text { merah } 1: 6\end{array}$ & 17 & 12 & 5 & 2 & 2 & $22,440,000$ \\
\hline $\begin{array}{l}\text { Pek. Kap Atap } \\
\text { Galvalum } \\
\text { Fabrikasi }\end{array}$ & 6 & 9 & 5 & 2 & 2 & $6,930,000$ \\
\hline $\begin{array}{l}\text { Pas. Genteng } \\
\text { Fabrikasi }\end{array}$ & 4 & 14 & 8 & 2 & 2 & $6,560,000$ \\
\hline $\begin{array}{l}\text { Pas. Genteng } \\
\text { Bubungan } \\
\text { Fabrikasi }\end{array}$ & 3 & 15 & 8 & 2 & 2 & $5,085,000$ \\
\hline
\end{tabular}

Dari data tabel 6, 7, dan 8, didapatkan prosentase biaya dan waktu sebagai berikut ;

Contoh Perhitungan :

- Cut and Crash 1

Diketahui :

Jumlah seluruh kegiatan $=83$ Kegiatan Jumlah Kegiatan dipercepat $=5$ Kegiatan Biaya Normal $=$ Rp. 345.390.000,00

Biaya total dari 83 kegiatan setelah $\mathrm{Cut}$ and Crash $1=$ Rp. 347.935.000,00 Prosentase Pengurangan Biaya $=5: 83 \times 100 \%=6,02 \%$

Prosentase Pertambahan Biaya $=(347.935 .000-345.390 .000):$ $345.390 .000 \times 100 \%$ $=0,68 \%$

- $\quad$ Cut and Crash 2

Diketahui :

Jumlah seluruh kegiatan $=83$ Kegiatan Jumlah Kegiatan dipercepat $=2$ Kegiatan Biaya Normal $=$ Rp. $345.390 .000,00$ Biaya totaldari 83 Kegiatan Setelah $\mathrm{Cut}$ and Crash $2=$ Rp. 348.015.000,00 Prosentase Pengurangan Biaya $=2: 83 \times 100 \%=2,41 \%$

Prosentase Pertambahan Biaya $=(348.015 .000-345.390 .000):$ $345.390 .000 \times 100 \%$ $=0,70 \%$

- Cut and Crash 3

Diketahui :

Jumlah seluruh kegiatan $=83$ Kegiatan Jumlah Kegiatan dipercepat $=7$ Kegiatan Biaya Normal $=$ Rp. 345.390.000,00 Biaya total dari 83 Kegiatan Setelah Cut and Crash $3=$ Rp. 350.360.000,00

Prosentase Pengurangan Biaya $=7: 83 \times 100 \%=8,43 \%$

Prosentase Pertambahan Biaya $=(350.360 .000-345.390 .000):$

$345.390 .000 \times 100 \%$ $=1,38 \%$

Tabel. 9

Rekapitulasi Prosentase Biaya dan Durasi Proyek

\begin{tabular}{ccccc} 
TAHAP & $\begin{array}{c}\text { BIAYA } \\
(\mathbf{R p})\end{array}$ & WAKTU & $\begin{array}{c}\text { PERTAM- } \\
\text { BAHAN } \\
\text { BIAYA } \\
(\boldsymbol{\%})\end{array}$ & $\begin{array}{c}\text { PENGU- } \\
\text { RANGAN } \\
\text { DURASI } \\
(\boldsymbol{\%})\end{array}$ \\
\hline Normal & $345,390,000$ & 89 & & \\
\hline
\end{tabular}




\begin{tabular}{lcccc}
\hline TAHAP & $\begin{array}{c}\text { BIAYA } \\
(\mathbf{R p})\end{array}$ & WAKTU & $\begin{array}{c}\text { PERTAM- } \\
\text { BAHAN } \\
\text { BIAYA } \\
(\%)\end{array}$ & $\begin{array}{c}\text { PENGU- } \\
\text { RANGAN } \\
\text { DURASI } \\
(\%)\end{array}$ \\
\hline $\begin{array}{l}\text { Cut and } \\
\text { Crash 1 }\end{array}$ & $347,935,000$ & 82 & 0.68 & 6.02 \\
\hline $\begin{array}{l}\text { Cut and } \\
\text { Crash 2 }\end{array}$ & $348,015,000$ & 88 & 0.70 & 2.41 \\
\hline $\begin{array}{l}\text { Cut and } \\
\text { Crash 3 }\end{array}$ & $350,360,000$ & 82 & 1.38 & 8.43 \\
\hline
\end{tabular}

Sumber: Hasil Perhitungan

\section{Membuat Grafik TPD}

Berdasarkan Tabel 6 dapat dibuat grafik hubungan antara titik normal dan TPD untuk mempermudah memilih serta membandingkan waktu dan biaya sebelum dan sesudah percepatan, sepertipada gambar 2.

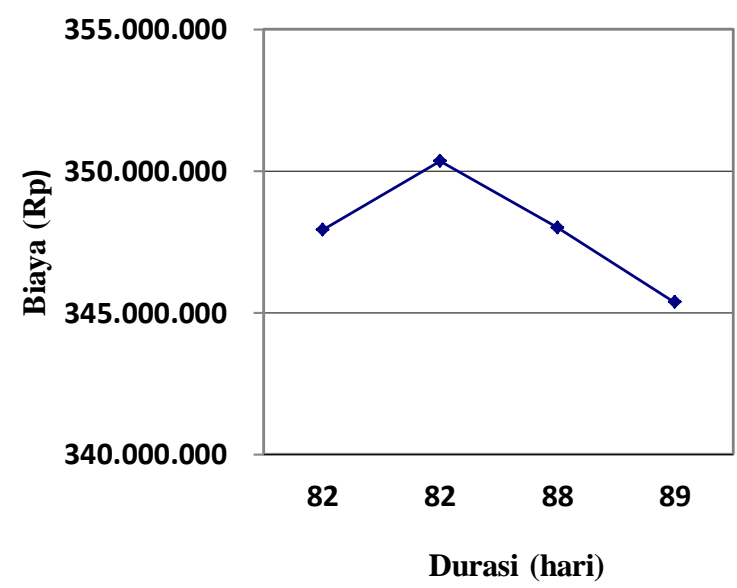

Gambar. 2

Grafik Titik Proyek Dipercepat

\section{Pemilihan Waktu dan Biaya Efektif Setelah Percepatan}

Dari grafik TPD, maka tujuan penelitian telah dicapai. Dengan demikian dipilih proses cut and crash pertama karena dari ketiga proses cut, cut and crash 1 memiliki durasi dan biaya paling efisien setelah adanya percepatan. Pada cut and crash 1 durasi proyek dapat dipercepat hingga 82 hari atau 7 hari lebih cepat dengan biaya tenaga kerja mencapai Rp. 347.935.000,00.(Sumber : Hasil Analisis)

\section{KESIMPULAN}

Kesimpulan yang dapat diambil dari hasil analisis metode cut and crash yang telah dilakukan pada pelaksanaan proyek Pembangunan Puskesmas Laren ialah bahwa :

1. Lama waktu paling cepat akibat percepatan proyek menggunakan metode jaulur kritits cut and crash adalah 82 hari atau 7 hari lebih cepat dari hari normal 89 hari. Sehingga dengan dilakukan penelitian ini, pekerjaan dapat terselesaikan pada tanggal 13 Desember 2016.

2. Besar biaya akibat percepatan proyek menggunakan metode jalur kritis adalah sebesar Rp. 347.935.000,00 atau mengalami kenaikan Rp. 2.545.000,00 dari biaya normal $\mathrm{Rp}$. 345.390.000,00. Sehingga dengan dengan dilakukan penelitian ini, biaya yang dikeluarkan lebih besar sebagai akibat percepatan.

3. Besarnya prosentase perbandingan akibat adanya percepatan proyek menggunakan metode jalur kritis cut and crash yaitu, untuk waktu percepatan sebesar $6,02 \%$ lebih cepat dari waktu normal, sedangkan untuk biaya percepatan ialah $0,68 \%$ lebih besar dari biaya normal. Sehingga dengan dilakukan penilitian ini, biaya yang dikeluarkan menjadi lebih mahal, akan tetapi waktu penyelesaian proyek menjadi lebih singkat dan lebih ringkas.

\section{REFERENSI}

Djojowirono, S. 2000. Manajemen Konstruksi 1. Yogyakarta : Biro Penerbit KMTS Universitas Gajah Mada.

Frederika, Ariany. 2010. Analisis Percepatan Pelaksanaan Dengan Menambah Jam Kerja Optimum Pada Proyek Konstruksi (Studi Kasus: Proyek Pembangunan Super Villa, Peti Tenget -Badung). Bali : Universitas Udayana.

Rosadi, Tiara Marlita, Benny Mochtar dan Rosa Agustianah. Analisa Efisiensi antara Waktu dan Biaya Percepatan Pelaksanaan pada Kegiatan Pembangunan Jala H.M Ardan di Kota Samarinda.Samarinda : Universitas17 Agustus 1945 Samarinda 
Soeharto, Imam. 1995. Manajemen Proyek (dari Konseptual Sampai Operasional). Jakarta : Erlangga

Soeharto, Imam. 1997. Manajemen Proyek (dari Konseptual Sampai Operasional) Jilid 1. Edisi 2. Jakarta : Erlangga 
Halaman ini sengaja dikosongkan 